\title{
Outcome of Traumatic Subarachnoid Hemorrhage in Patients Presenting to Neurosurgery Department Lady Reading Hospital Peshawar
}

\author{
MUHAMMAD ISHFAQ,${ }^{1}$ MUMTAZ ALI, ${ }^{2}$ MUHAMMAD AHMED ALFAQEEH, ${ }^{3}$ SAUD \\ ALNASHRI ${ }^{4}$ \\ ${ }^{1}$ Department of Neurosurgery, ${ }^{2}$ Department of Neurosurgery, Lady Reading Hospital Peshawar, KPK, \\ Pakistan, ${ }^{3}$ Umm AlQura University Qunfudah Makkah Region, ${ }^{4}$ Qunfudah General Hospital, KSA,
}

\begin{abstract}
Objective: To know about outcome of Traumatic Subarachnoid Hemorrhage based on Glasgow outcome scale at the time of discharge from the hospital.

Material and Methods: We conducted prospective observational study at Neurosurgery Department Lady Reading Hospital Peshawar from January 2016 to June 2016 with total 6 months' duration. All patients with traumatic subarachnoid hemorrhage having both genders and having age from 10 to 60 years were included. Patients with sub arachnoid hemorrhage due to aneurysm, AVM, brain tumors, neuroinfections, anticoagulants, sickle cell anemia and having other forms of traumatic brain injuries were excluded. SPSS version 20 was used for data analysis and showed in the form of tables and graphs.
\end{abstract}

Results: $48 \%$ patients were in age group from $2^{\text {nd }}$ to $4^{\text {th }}$ decade while $19 \%$ had age $<2^{\text {nd }}$ decade and remaining $33 \%$ patients age > 40 years. 32 years $\pm 2.12 S D$ was the mean age for all patients. $72 \%$ patients were male and $28 \%$ females. RTA (58.97\%) was most common cause and majority of the patients initially at arrival were in the GCS range of 3 to $8(74.74 \%)$. At the discharge from the hospital $60 \%$ patients had unfavorable traumatic subarachnoid hemorrhage while $40 \%$ patients had favorable traumatic subarachnoid hemorrhage.

Conclusion: Our study concluded that the frequency of unfavorable traumatic subarachnoid hemorrhage is higher in KPK as compare to other international studies because of severity of the trauma, late presentation of the patients in the hospital, less community education about traumatic brain injuries, short time of follow up, Deficiency of neurosurgical icu,s in our set up.

Key Words: Outcome, Traumatic, Subarachnoid Hemorrhage.

Abbreviations: tSAH: Traumatic Subarachnoid Hemorrhage. GCS: Glasgow Coma Scale. GOS: Glasgow Outcome Scale. KPK: Khyber Pakhtun Khwa. GOS; E: Extended Glasgow Outcome Scale. TBI: Traumatic Brain Injury. TCD: Trans cranial Doppler. ATLS: Advanced Trauma Life Support. AVM: Arteriovenous Malformation. RTA: Road Traffic Accidents.

\section{INTRODUCTION}

In population having age less than 45 years' head injury is considered in one of the leading causes of morbidity and mortality. Head injury is responsible for $70 \%$ deaths in trauma patients and furthermore those who remain alive after trauma the permanent disabilities are mostly due to the head injuries. ${ }^{1}$ Approximately 100 billion dollars are spent every year on patients of head injuries in United States.$^{2}$ When a person sustains head injury the protocols of both basic and advanced life support are applied even at the site of the scene by prehospital person and it has a positive effect on the outcome of patients. It has been proved 
by the studies that application of ATLS protocols on head injury patients at the scene of injury are extremely important for patient's future functional outcome and betterment. ${ }^{3}$ Traumatic subarachnoid hemorrhage (tSAH) has a high incidence $(61 \%)$ in patients with TBI. It can carry a poor prognosis however; prognosis can vary significantly according to the grading of Traumatic subarachnoid hemorrhage (tSAH) and the severity of CT findings. ${ }^{4}$

Those patients who have only traumatic subarachnoid hemorrhage have more favorable prognosis than those who have associated other types of head injuries like contusion, subdural and epidural hematomas this is why it is mandatory to refer those patients with associated other types of head injuries more vigorously to specialized neurosurgical centers so they can be treated on time in the hope of better outcome. ${ }^{5}$ Glasgow coma scale of patients after trauma , age of the patients, extent oftraumatic subarachnoid hemorrhage (tSAH) and extension of blood into the ventricles of brain are extremely important for outcome of patients after diagnosis of traumatic subarachnoid. Cerebral vasospasm has more chances to occur if there is extensive subarachnoid hemorrhage. ${ }^{6}$ Traumatic brain injury is considered as a high risk event in patients having age $>70$ years if he is on anti-coagulant therapy with associated accidental fall and additionally if traumatic subarachnoid hemorrhage is detected on CT brain then its mortality rate increases furthermore. ${ }^{7}$ The precision and accuracy in diagnosis of traumatic sub arachnoid hemorrhage increases if highly qualified radiologist and latest generation computed tomographic scan is available while it is done within the 6 hours of the onset of headache. ${ }^{8}$ Regarding thickness of sub arachnoid hemorrhage on CT it is regarded as a major independent prognostic factor for mortality. Anatomical distribution per se did not affect clinical outcome. ${ }^{9}$ Traumatic subarachnoid hemorrhage has profound effect on persistent cognitive disturbance of patients after recovery from acute stage of head injury. Initial Glasgow coma scale (GCS)and extended Glasgow outcome scale (GOS-E) on the follow up the extent of tSAH is the main variable which is responsible for cognitive deficits which occurs after head injuries an independent risk. ${ }^{10}$ Nowadays Glasgow Outcome Scale (GOS) is an acceptable option for the assessment of prognosis after head injury but still there are some deficiencies in it and it can be overcome by following the standard format while interviewing the patients. ${ }^{11}$ The favorable outcome of the traumatic subarachnoid hemorrhage (tSAH ) is reported in literature from $45 \%^{12}$ to $58 \%^{10}$ and unfavorable outcome ranges from $47.5 \%^{6}$ to $55 \% .^{12}$

\section{MATERIAL AND METHODS}

After permission from hospital ethical committee, patients with traumatic subarachnoid hemorrhage admitted in Neurosurgery Department of Lady Reading Hospital was approached. All those patients who were included in the study a written informed consent was explained to them and then signed. After this they were assessed by history specially asking the variables like name, age, gender, residential address, signs and symptoms, duration of symptoms, initial GCS score and diagnosis of tSAH was made on the basis of CT brain.The decision for admission of patients whether to admit in neurosurgical ward or in ICU was made mainly on patient's clinical status. The patients were assessed at the time of discharge from the hospital and were categorized as either favorable having GOS 4 or 5 or unfavorableoutcome having GOS 3 or less. An exclusion criterion was followed strictly on all patients. SPSS version 20 was used to analyze the data and based on category just like descriptive variables mean \pm standard deviation was used for age and initial GCS while for categorical variables percentages and frequencies were used for gender. Furthermore, outcome was stratified among age and gender of patients. Results were presented in tables and charts for different variables.

\section{RESULTS}

195 patients fulfilled the inclusion criteria among 37 (19\%) patients age was < 20 years, 94(48\%) had 21-40 years, $45(23 \%)$ were in age range of 41-60 years while $19(10 \%)$ patients age was $>60$ years. The mean age was 32 years $\pm 2.12 \mathrm{SD}$ (Table 1$)$. Patients were also

Table 1: Age of the patients $(n=195)$.

\begin{tabular}{|l|c|c|}
\hline Age of Patients & Frequency & Percentage \\
\hline$<20$ years & 37 & $19 \%$ \\
\hline $21-40$ years & 94 & $48 \%$ \\
\hline $41-60$ years & 45 & $23 \%$ \\
\hline$>60$ years & 19 & $10 \%$ \\
\hline
\end{tabular}




\begin{tabular}{|l|c|c|}
\hline Total & 195 & $100 \%$ \\
\hline
\end{tabular}

Mean age was 32 years with $\mathrm{SD} \pm 2.12$

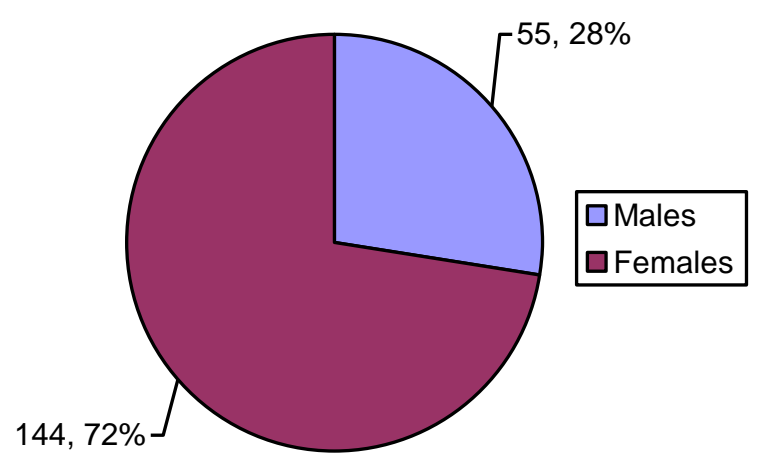

Fig. 1: Gender distribution $(n=195)$.

Table 2: Etiology of Traumatic Subarachnoid Hemorrhage $(n=195)$.

\begin{tabular}{|l|c|c|}
\hline Etiology & $\begin{array}{c}\text { Number of } \\
\text { Patients }\end{array}$ & $\begin{array}{c}\text { Percentage of } \\
\text { Patients }\end{array}$ \\
\hline RTA & 115 & 58.97 \\
\hline Fall from height & 55 & 28.20 \\
\hline Blunt trauma & 25 & 12.82 \\
\hline
\end{tabular}

divided in groups according to the gender in which male's patients were 140 (72\%) so effected more than females (Fig. 1). Regarding etiology of traumatic sub arachnoid hemorrhage, the leading cause was RTA having $115(58.97 \%)$ followed by fall from height with $55(28.20 \%)$ and minimum number of cases were that of blunt trauma having 25 (12.82\%) (Table 2).

Initial GCS score at the time of admission was from 3 to 8 in $138(70.76 \%)$ patients while 9 to 15 in $57(29.4 \%)$ patients (Table 3$)$. Traumatic subarachnoid hemorrhage among 195 patients was analyzed as 117
Table 3: Initial GCS at the Time of Admission ( $n=$ 195).

\begin{tabular}{|c|c|c|}
\hline Initial GCS & No of Patients & $\begin{array}{c}\text { Percentage of } \\
\text { Patients }\end{array}$ \\
\hline $3-8$ & 138 & 70.74 \\
\hline $9-15$ & 57 & 29.26 \\
\hline
\end{tabular}

Mean GCS score was 7 with $\mathrm{SD} \pm 2.1$

(60\%) patients had unfavorable traumatic subarachnoid hemorrhage with GOS $\leq 3$ while 78 (40\%) patients had favorable traumatic subarachnoid hemorrhage with GOS > 3 (Table $4 \& 5$ ). The outcome of traumatic subarachnoid hemorrhage was also categorized according to age and gender whichhave been given in (Tables 6, 7).

Table 4: GOS at the Time of Discharge from the Hospital $(n=195)$.

\begin{tabular}{|c|c|c|}
\hline $\begin{array}{c}\text { GOS Score at the } \\
\text { Time of Discharge }\end{array}$ & Frequency & Percentage \\
\hline$\leq 3$ & 117 & $60 \%$ \\
\hline$>3$ & 78 & $40 \%$ \\
\hline Total & 195 & $100 \%$ \\
\hline
\end{tabular}

Mean GOS score was 3 with SD \pm 1.78

Table 5: Outcome of Traumatic Subarachnoid Hemorrhage $(n=195)$.

\begin{tabular}{|l|c|c|}
\hline Outcome & Frequency & Percentage \\
\hline Un Favorable & 117 & $60 \%$ \\
\hline Favorable & 78 & $40 \%$ \\
\hline Total & 195 & $100 \%$ \\
\hline
\end{tabular}

Table 6: Stratification Outcome of Traumatic Subarachnoid Hemorrhage $(n=195)$.

\begin{tabular}{|l|c|c|c|c|c|}
\hline Outcome & < 20 Years & $\mathbf{2 1 - 4 0}$ Years & 41-60 Years & > 60 Years & Total \\
\hline Un Favorable & 22 & 56 & 27 & 12 & 117 \\
\hline Favorable & 15 & 38 & 18 & 7 & 78 \\
\hline
\end{tabular}


Outcome of Traumatic Subarachnoid Hemorrhage in Patients Presenting to Neurosurgery Department Lady Reading

\begin{tabular}{|l|l|l|l|l|l|}
\hline Total & 37 & 94 & 45 & 19 & $100 \%$ \\
\hline
\end{tabular}

Chi Square test was applied in which $\mathrm{P}$ value was 0.003 
Table 7: Stratification Outcome of Traumatic Subarachnoid Hemorrhage with Respect to Gender $(n=195)$.

\begin{tabular}{|l|c|c|c|}
\hline Outcome & Male & Female & Total \\
\hline Un-Favorable & 84 & 33 & $117 \%$ \\
\hline Favorable & 56 & 22 & $78 \%$ \\
\hline Total & 140 & 55 & $100 \%$ \\
\hline
\end{tabular}

Chi Square test was applied in which P value was 0.002

\section{DISCUSSION}

In population having age less than 45 years' head injury is considered in one of the leading causes of morbidity and mortality. Head injury is responsible for $70 \%$ deaths in trauma patients and furthermore those who remain alive after trauma the permanent disabilities are mostly due to the head injuries ${ }^{1}$. Approximately 100 billion dollars are spent every year on patients of head injuries in United States. ${ }^{2}$

195 patients fulfilled the inclusion criteria among which 37 (19\%) patients age was < 20 years, 94 (48\%) had 21-40 years, 45 (23\%) were in age range of 41-60 years while $19(10 \%)$ patients age was $>60$ years. The mean age was 32 years \pm 2.12 SD. Patients were also divided in groups according to the gender in which male's patients were $140(72 \%)$ so effected more than females having males to females ratio of $2.69 ; 1$. Phelan HA and colleagues ${ }^{13}$ in their study of 102 patients of isolated traumatic sub arachnoid hemorrhage has shown that the mean age of the patients was $42.5 \pm 19.2 \mathrm{SD}$ and the total number of males (71) were greater than females (29) with the males to females ratio of 2.24:1. Similarly In studies of Rubino $\mathrm{S}^{14}$ and Harvey LA and colleagues ${ }^{15}$ the mean age of the traumatic sub arachnoid hemorrhage is greater than our study while in both studies males were predominantly affected due to traumatic sub arachnoid hemorrhage. Our results resemble with them in terms of males to female's ratio but the mean age of the patients was greater than patients in our study.

In our region traffic rules regulations are not followed properly, Roads infra-structure is not fully developed, Transport vehicles are not properly maintained and these are also fully loaded with passengers, Peoples specifically younger population who ride motor bikes on the roads did not wear protective helmets, increase poverty, less education ratio and more job less ratio as compared to European countries therefore peoples migrate to work in the major cities in order to earn the money for the whole family in very young age therefore they suffer more in early age from traumatic subarachnoid hemorrhage due to RTA's, falls etc.

Nowadays Increased mortality and morbidity due to road traffic accidents has become a serious issue. In KPK most of the trauma patients received in trauma centers are due to road traffic accidents and the same picture was also dominant in our study such that most of the patients of traumatic sub arachnoid hemorrhage in our study were due to road traffic accidents which were $115(58.97 \%)$ followed by the fall from the height which had 55 (28.20\%). In study of Paiva WS et $\mathrm{al}^{12}$ the leading cause of traumatic sub arachnoid hemorrhage was road traffic accidents having 87 (72\%) cases followed by fall from the height with 27 $(23 \%)$ cases. Similarly Okten AI1 et al ${ }^{16}$ had shown that the etiology of tSAH included traffic accidents (73\%) on the top, then falls (20\%) and others (7\%). So our results resemble these two based on etiology. We received major bulk of patients with low GCS in range of 3 to 8 having $138(70.74 \%)$ cases while remaining $57(29.26 \%)$ were from 9-15. In the same study of Okten Ail et $\mathrm{al}^{16} 52 \%$ of the patients were initially with low GCS from 3 to 8 and $48 \%$ were in the range of 9 to 15 . Similarly Lee JJ and colleagues ${ }^{17}$ in their study conducted on isolated traumatic sub arachnoid hemorrhage have also documented that majority of the patients $53 \%$ of the total presented initially with GCS 3 to 8 . In our series the total number of patients with GCS 3 to 8 at the time of presentation are more as compared to previous two series this is because in KPK major population is located in the periphery due to which arrival to the tertiary care hospitals is late due to many problems along with deficient pre hospital management and lake of ATLS protocols application.

So the patient's in spite of initial good consciousness level become deteriorated then presented to us. Outcome of traumatic sub arachnoid hemorrhage in all 195 patients was assessed by using Glasgow Outcome Score while discharging the patients from the hospital. Among these 117 (60\%) patients had unfavorable outcome and remaining 78 (40\%) patients with favorable outcome. Paiva WS and colleagues $^{12}$ prospectively followed 121 patients of traumatic subarachnoid hemorrhage (tSAH) being diagnosed on non-contrast CT scan of the brain from January 2004 to January 2007 which were admitted to their trauma intensive care unit. They classified all cases of tSAH by applying the criteria of Fisher scale 
along and then followed all the patients till to 6 months after initial injury on regular basis by assessing the patients by means of Glasgow outcome scale. At the end of the follow up session they noted thatin 54 $(45 \%)$ patient's outcome was favorableand unfavorable outcome was documented in $67(55 \%)$ patients.

In Chinese population outcome of traumatic sub arachnoid hemorrhage was assessed by Wong GKC and colleagues. ${ }^{10}$ They followed 41 patients till to the 5 years out of total 111 patients and remaining 70 were unable to do the proper follow up due to different reasons. GOS was used for outcome measurement. At the end of follow up session favorable outcome was noted in $58 \%$ of patients and remaining $42 \%$ patients suffered from unfavorable outcome. In another series ${ }^{16}$ the neurological outcomes of patients in 59\% patients was favorable and unfavorable in $41 \%$ according to GOS.In available literature it has been documented that those head injury patients who have associated traumatic subarachnoid hemorrhage has more poor outcome than those who have only traumatic brain injury without it. Subsequent changes after traumatic subarachnoid hemorrhage just like cerebral vasospasm and ischemia are the main causes which lead to poor outcome in approximately $40 \%$ of severe TBI patients. ${ }^{17}$ Lin $\mathrm{TK}^{6}$ in their series have also shown the same cause of deterioration in patients having traumatic subarachnoid hemorrhage.Their study was basically an associative type of study in which they studied the correlation between cerebral vasospasm after traumatic subarachnoid hemorrhage and clinical status of patients in 117 patients. They categorized the patients in 4 groups among them Group I patients were those in which traumatic sub arachnoid hemorrhage was detected in the region of posterior interhemispheric fissure, Group II patients with traumatic sub arachnoid hemorrhage located elsewhere. Group II patients were categorized further in sub groups based on extent of traumatic sub arachnoid hemorrhage in which IIa were those having small amount of sub arachnoid hemorrhage, II b with extensive, II c had small subarachnoid hemorrhage but extension to ventricular systems and IId were characterized by extensive sub arachnoid hemorrhage with extension to ventricular systems. Trans cranial Doppler sonography was used for measuring the velocity of cerebral blood flow.

According to their study observations the outcome of traumatic subarachnoid hemorrhage was more poor in those patients in whom extension was more both in terms of ventricular involvement and without it as compared to those patients in which it was less extensive and no involvement of ventricles. They noted that poor outcome was $7.4 \%$ in group I, $18.4 \%$ in IIb, $33.3 \%$ in IIc, and IId had $90.9 \%$. They further categorized the outcome of patients based on extension and isolated involvement of ventricular systems in which those patients who had isolated extensive tSAH (group IIb + IId) without involvement of ventricular system had poor outcome that of $47.7 \%$ while those with little traumatic sub arachnoid hemorrhage without involving the ventricles (group IIa + IIc) poor outcome was noted in $26.1 \%$. Furthermore, isolated involvement of ventricles had also poor outcome than those in which the ventricular system was not involved. Group IIc + IIdhaving isolated intra ventricular hemorrhage after trauma had $78.9 \%$ poor outcome which is much higher than those having no intraventricular hemorrhage after sustaining head injury from trauma. So group IIa + IIb patients who have no intraventricular hemorrhage the total number of patients were $25.4 \%$ with poor outcome. On trans cranial Doppler study $37.5 \%$ patients of group IIb and IId who had extensive traumatic subarachnoid hemorrhage on CT brain were found to have cerebral vasospasm while patients in group I with $5.9 \%$ poor outcome and those of group IIa + IIc patients had $7.7 \%$.

When clinical outcome was correlated with the findings of cerebral vasospasm on trans cranial Doppler ultrasound it was found that those patients who had cerebral vasospasm detected on trans cranial Doppler ultra sound had poor outcome $(47.4 \%)$ than those who have no cerebral vasospasm on trans cranial Doppler ultrasound of the brain (24.7\%).

From all the above studies to which the results of outcome were compared our patients suffered slightly more from the unfavorable outcome except from Lin TK. ${ }^{6}$ This is because majority of our patients presented to us with low GCS due to late to late arrival, deficient pre hospital management, lake of ATLS protocols superimposed by deficient neurocritical care facilities in our hospital.According to the Servadei $\mathrm{F}^{18}$ the outcome of traumatic subarachnoid hemorrhage was strongly associated with presence or absence of subarachnoid hemorrhage on CT brain because in their series $41 \%$ patients having no subarachnoid hemorrhage on CT brain attained good recovery while in those having subarachnoid hemorrhage only $15 \%$ patients were able to achieve good recovery. Additionally they also found that patients with poor outcome were older than those having good outcome 
and the same tendency of poor outcome along with increasing age was also noted in our series.

\section{CONCLUSION}

In our set up patients who present with traumatic subarachnoid hemorrhage have poor outcome as compared to developed countries because of severity of the trauma, late presentation of the patients to the tertiary care hospitals, deficient ATLS protocols in pre hospital stage and lake of full arrangement of neurointensive care units for the patients even in tertiary care hospitals. If these barriers are overcome along with the community education and proper legislation of traffic rules the mortality and morbidity due to traumatic subarachnoid hemorrhage can be significantly reduced.

Address for Correspondence:
Dr Muhammad ishfaq
Department of Neurosurgery
South Al-Qunfudah General Hospital, KSA
E mail: Ishfaqktk83@ gmail.com.
Cell No. 03348277230, 03000576353
Cell No in KSA: 0096582462181

\section{REFERENCES}

1. Islam MJ, Saha SK, Elahy MF, Islam KMT, Ahmed SU. Factors influencing the outcome of patients with acute extradural hematoma undergoing surgery. Bangladesh J Med Sci. 2011; 10 (2): 112-20.

2. Islam MM, Bhuiyan TH, Hassan MK, Asadullah MATM, Raihan Z, Hossain SS, et al. Management strategy and outcome of epidural hematoma in relation to volume. Faridpur Med Coll J. 2011; 6 (2): 89-91.

3. Tallon JM, Ackroyd Stolarz S, karim SA, Clark DB. The epidemiology of surgically treated acute subdural and epidural hematomas in patients with head injuries: a population-based study. Can J Surg. 2008; 51 (5): 339-45.

4. Silva MD, Brazis P, Millar D, Wharen R, Smith CC, Freeman WD. A delayed onset, complete third-nerve palsy after traumatic subarachnoid hemorrhage. J VascInterv Neurol. 2013; 6 (1): 22-5.

5. Borczok P, Penn J, Peak S, Chang Y. Patients with traumatic subarachnoid hemorrhage are at low risk for deterioration or neurosurgical intervention. J Trauma Acute Care Surg. 2013; 74 (6): 1504-9.

6. Lin TK, Chieh, Hsieh HT, Tsung C. The impact of traumatic subarachnoid hemorrhage on outcome: A study with grouping of traumatic subarachnoid hemorrhage and trans-cranial doppler sonography. J Trauma Acute Care Surg. 2012; 73 (1): 131-6.
7. Gaetani P, Reavy M, Sciacca S, Pessani F, Aimer E, Levi D, et al. Traumatic brain injury in the elderly: considerations in a series of 103 patients older than 70 . J Neurosurg Sci. 2012 Sep; 56 (3): 231-7.

8. Perry JJ, Stiell IG, Sivilotti ML, Bullard MJ, Emond M, Symington C, et al. Sensitivity of computed tomography performed within six hours of onset of headache for diagnosis of subarachnoid hemorrhage: prospective cohort study. BMJ. 2011; 343: 4277.

9. Wong GKC, Yeung GH, Graham CA, Zhu XL, Rainer TH, Poon WS, et al. Neurological outcome in patients with traumatic brain injury and its relationship with computed tomography patterns of traumatic subarachnoid hemorrhage. J Neurosurg. 2011; 114 (6): 1510-5.

10. Wong GKC, Ngai K, Wong A, Lam SW, Mok VC, Yeung $\mathrm{J}$, et al. Long-term cognitive dysfunction in patients with traumatic subarachnoid hemorrhage: prevalence and risk factors. Acta Neurol. 2012; 154 (1): $105-11$.

11. Wilson JT, Pettigrew LE, Teasdale GM. Structured interviews for the glasgow outcome scale and the extended glasgow outcome scale: guidelines for their use. J Neurotrauma. 2009; 15 (8): 1-10.

12. Paiva WS, De Anderade AF, De amorim RL, Muniz RK, Paganelli PM, Bernar LS. The prognosis of the traumatic subarachnoid hemorrhage: a prospective report of 121 patients.Int Surg. 2010; 95 (2): 172-6.

13. Phelan HA, Richter AA, Scott WW, Pruitt JH, Madden CJ, Rickert KL, et al. Does isolated traumatic subarachnoid hemorrhage merit a lower intensity level of observation than other traumatic brain injury? J Neurotrauma. 2014; 31 (20): 1733-6.

14. Rubino S, Zaman RA, Sturge CR, Fried JG, Desai A, Simmons NE, et al. Outpatient follow-up of nonoperative cerebral contusion and traumatic subarachnoid hemorrhage: does repeat head CT alter clinical decision-making? J Neurosurg. 2014 Oct; 121 (4): 944-9.

15. Harvey LA, Close JC. Traumatic brain injury in older adults: characteristics, causes and consequences. Injury, 2012; 43 (11): 1821-6.

16. Okten AI1, Gezercan Y, Ergün R. Traumatic subarachnoid hemorrhage: a prospective study of 58 cases. Ulus Travma Acil Cerrahi Derg. 2006 Apr; 12 (2): 107-14.

17. Lee JJ, Segar DJ, Asaad WF. Comprehensive assessment of isolated traumatic subarachnoid hemorrhage. J Neurotrauma. 2014 Apr. 1; 31 (7): 595609.

18. Servadei F, Murray GD, Teasdale GM, Dearden M, Iannotti F, Lapierre F,et al . Traumatic subarachnoid hemorrhage: demographic and clinical study of 750 patients from the European brain injury consortium survey of head injuries. Neurosurg. 2002 Feb; 50 (2): 261-7. 
AUTHORS DATA

\begin{tabular}{|c|c|c|c|c|}
\hline Name & Post & Institution & E-mail & Role of Authors \\
\hline Dr. Muhammad Ishfaq & $\begin{array}{l}\text { Senior } \\
\text { Registrar }\end{array}$ & $\begin{array}{c}\text { Department of Neurosurgery, } \\
\text { South Al-Qunfudah General } \\
\text { Hospital, KSA }\end{array}$ & Ishfaqktk83@gmail.com. & $\begin{array}{l}\text { Paper Writing } \\
\text { and Literature } \\
\text { Search }\end{array}$ \\
\hline Dr. Muhammad Alfaqeeh & Resident & \multirow{2}{*}{$\begin{array}{c}\text { Department of Surgery, South } \\
\text { Al-Qunfudah General } \\
\text { Hospital, KSA }\end{array}$} & & Data Collection \\
\hline Dr. Saud Alnashri & $\begin{array}{l}\text { House } \\
\text { officer }\end{array}$ & & & $\begin{array}{l}\text { Tables and } \\
\text { Graphs }\end{array}$ \\
\hline Dr. Mumtaz Ali & & $\begin{array}{c}\text { Department of Neurosurgery, } \\
\text { Lady Reading Hospital } \\
\text { Peshawar, KPK, Pakistan }\end{array}$ & & $\begin{array}{l}\text { Overall } \\
\text { Supervision }\end{array}$ \\
\hline
\end{tabular}

Date of Submission: 16-11-2018

Date of Printing: 15-12-2018 